\title{
Examination of Risk Factors in the Healthcare Product Development Process by using Fuzzy based MCDM Method
}

\author{
R.K.A.Bhalaji, S. Bathrinath, S. Saravanasankar
}

\begin{abstract}
Healthcare product development (HCPD) process is generally long and time taking process because of complex manufacturing systems. These intricacy systems, the amount of risks involved in product development is also high. It is very much essential in controlling/minimizing risk in this process. The aim of this paper is to investigate risks in an herbal soap manufacturing company under HCPD to suggest a ranked risk structure (RRS) portrayal for obtaining the subjective risk assessment to change the magnitude of risks. For transforming the linguistic data into numeric risk ratings, a fuzzy based MCDM technique is used in this paper and also computing the 'Level of risk' regarding crisp ratings, a method of 'Incentre of Centroids' for GTrFN has been used. Lastly, a structure to sort dissimilar risk factors was suggested based on the notable extent of risk ratings (crisp). Subsequently, an action strategy was proposed to provide instructions to company managers to effectively control risks. A case study tactic is employed.
\end{abstract}

Keywords: HCPD process, Risk assessment, RRS.

\section{INTRODUCTION}

$\mathrm{H}$ ealthcare products are essential for surviving in the world. Nowadays, customers using herbal products instead of routine bath soaps with chemical ingredients since the natural/herbal based soap products aids to biologically moisten the skin, maintaining skin and hands smooth. Therefore, the herbal product companies are increasing day by day and lot of competition between them to show which company produce the best items. So, the development of healthcare product is vital to improve product quality which increases the reputation of the company. In our case, the risks are very risk in the initial stages of HCPD but in the middle stage the severity of risks is continuously increasing. The HCPD process should be well-designed and planned for lessening the number of risk occasions and their severities. Therefore, risk assessment is very essential to effectively improve the products inside manufacturing companies. By using this method, to control risks in the HCPD process for the development of healthcare products with predictable

Revised Manuscript Received on December 05, 2019.

* Correspondence Author

R.K.A.Bhalaji, Department of mechancical engineering, Kalasalingam Academy of research and education, Krishnankoil-626126, India. Email: bhalaji28@gmail.com

S.Bathrinath*, Department of mechancical engineering, Kalasalingam Academy of research and education, Krishnankoil-626126, India. Email: bathri@gmail.com

S.Saravanasankar, Department of mechancical engineering, Kalasalingam Academy of research and education, Krishnankoil-626126, India. Email: ssaravanasankar@klu.ac.in

quality and dependability. The method used in this paper will assist the experts, executives and academics for controlling the risks in the development process. Further, healthcare product development process and related information was studied by many researchers [1-3].

\section{RELEVANT LITERATURE}

A. Risk factors involved in product development process

Taylor and Ahmed-kristensen [4] analyzing the risks in product development process and also case study are conducted in two manufacturing companies. The outcomes will be useful for industrial managers, practitioners and researchers for developing and controlling the risks in product development process. Ajayi et al. [5] evaluated the risks and influence on product quality in the development process. The findings suggests that model for understanding the risk involved in the process and with the objective of improving product quality and distribution time. Choi and Ahn [6] evaluated the influencing risk drivers on PD process and will contribute towards the improvement of risk administration structure to defend against different risk drivers using fuzzy set theory and Markov technique. The result shows that it can be used to choosing the suitable responding activities to eliminate or reduce the potential impacts of the risk driver PD process. Chalupnik et al. [7] presented the technique to lessen the effect of ambiguity in PD process by using simulation tests. The result findings showed that they give valuable perceptions to develop PD process practically. Kayis et al. [8] created the risk alleviation technique for PD process and process plan in engg.schemes and it goals to be used as a judgment support utensil for scheme managers to choose the best alleviation plan dependent on the existing mitigation financial plan and scheme goals. The outcomes showed that the minimum cost risk ratio has the maximum cost effective solution. Unger and Eppinger [9] suggest a technique for enhancing PD process pattern and this technique used for controlling data streams, risks and iterations. The consequences indicated that having smart thoughts for brand-new products isn't sufficient; to effectively carry those products to marketplace, companies also want to pattern PD process that directs their particular requests. Zhang and Chu [10] recognizing and evaluating possible failures in PD process by using FMEA. The result displays that it may be useful for decision makers to establish the choosing principle in the process.

B. Risk factors involved in healthcare product development process

Shaw [11] performed the novelty and PD in the UK healthcare product company. 
From the above study, the outcomes indicates that rapidity and suppleness of the novelty process was based on the administration of an coinciding way at the various phases in the novelty sequence, the distributing of intense and data created both within the organization and from that skill entrenched in society and with exploration. Chan et al. [12] presented the quality assurance in the planning stage of healthcare PD by using failure investigation and Markov technique. The results suggested that it will considerably diminish the no of client grievances in relation to quality problems and product letdown rate. Kirkire et al. [13] investigated risks amid PD process in a healthcare product company and suggest a replica for risk alleviation to reduce failure occasions by using failure mode and effect analysis (FMEA) and fuzzy semantic technique. From the above study, the technique used in the study will aid the managers for controlling the risks amid PD process.

\section{Use of fuzzy number}

Muthuperumal et al. [14] performed the analysis on resolving (GTrFN) generalized trapezoidal fuzzy numbers using ranking method. The result showed that suggested technique with a descriptive arithmetical model to acquire the resolution to the trapezoidal fuzzy no's using ranking method. Kumar et al. [15] suggested the methodology to rank GTrFN. The outcome indicates that this methodology gives the GTrFN with absolute ranking and contrasted with various present methodologies.

\section{Literature gap}

As of now, there is no research papers related to analyzing the risk factors in the healthcare product development process by using fuzzy based multi-criteria decision making approach. Even though several papers projecting risk factors of HCPD process in general aspects, but these papers are inclined to be partial and frequently deteriorate to assess the most influential risk factor in the HCPD process. So to fulfill this gap, the paper analyzes the risk factors of HCPD process by using fuzzy based MCDM approach with the help of decision makers. The paper contains some highlights which are detailed as follows:

-This research highlights the risk factors that influence healthcare product development process. These risks must be identified and controlled for the sector to be viable and effective.

-In this study, a ranked risk structure portrayal was investigated to acquire a proper prototype for subjective risk assessment.

-Computing the 'level of risk' regarding crisp ratings, a method 'Incentre of centroids' for GTrFN has been used.

-Subsequently, an action strategy was proposed to provide instructions to industrial managers to effectively control risks in the healthcare product development process.

\section{RISK ASSESSMENT CONCEPT}

This paper has been portrayed the risk for the purpose of two key limits - (a) probability, which is the likelihood of an event and (b) influence, which is the level of severity. To compute the level of risk by using below equation.

$$
R=P \times I
$$

Here, I, R and P are the influence risk level, level and probability of the risk's happening. All are depicted within the interval $[0,1]$ where maximum signifies superior influence.

From Equation (1), if the risk factors has slight probability or influence of event at the risk level is nearby to zero. Additionally, if a risk factor possesses higher influence and higher event probability, its risk level is elevated i.e. near to one. By using the two tactics like objective analysis and individual decision, a probability of event can be assessed. As compared to analysis of objective, subjective decision is pragmatic and simple and it not has past statistics; it just requires some knowledge and inspection. So, this paper concentration on subjective decision process to evaluate both probability of event and the effect of every risk affecting factor.

\section{FUZZY SET METHODOLOGY}

Ranking of fuzzy numbers has a vital part in estimate decision making, optimization, scheduling and on the basis risk problems. Jain [16] initially proposed the fuzzy ranking method under the scenario of decision making. Wang and Kerre [17] categorized three kinds of ranking methods and suggested seven sensible possessions to assess ranking. Beside fuzzy number, Thorani et al. [18] provided a plan to compute corresponding crisp value. For ranking the fuzzy set numbers by using the calculated crisp score values. This notion is used to rank a set of fuzzy numbers with the aid of calculated crisp score. The notion of crisp assessment was investigated in this research to improve an effective risk assessment method. The mathematical foundation for this is given below.

For balancing the trapezoidal point considering the centroid of a trapezoid (Fig 2). To divide the trapezoidal plane diagrams into three elements which include a rectangle (QXYR), triangle (PXQ), (QXYR) and (RYS). Let To describe crisp values of GTrFN, the centroids of three plane diagrams $\mathrm{C} 1, \mathrm{C} 2$ and $\mathrm{C} 3$ are the point of reference. For the plane figures, every point as a balancing point that the motive for choosing as a point of reference and also as the balancing point for a GTrFN is Incentre point. Compared to trapezoid centroid point, the balancing point is the better one.

Let GTrFN's P = (p, q, r, s; v). The centroids of the three plane diagrams are

$$
C_{1}=\left(\frac{p+2 q}{3}, \frac{v}{3}\right), C_{2}=\left(\frac{q+r}{2}, \frac{v}{2}\right), C_{3}=\left(\frac{2 r+s}{3}, \frac{v}{3}\right)
$$

Equation of the line $\overline{C_{1} C_{3}}$ is $\mathrm{z}=\mathrm{v} / 3$ and $\mathrm{C} 2$ is not to be placed on the line $\overline{C_{1} C_{3}}$. Therefore, $\mathrm{C} 1 \mathrm{C} 2$ and $\mathrm{C} 3$ are in the shape of triangle and non-collinear.

With the vertices $\mathrm{C} 1, \mathrm{C} 2$ and $\mathrm{C} 3$, we define the incentre triangle of the GTrFN P $=(p, q, r, s ; v)$ as

$$
\begin{aligned}
& I_{p}\left(e_{0}, f_{0}\right)=\left(\frac{\mu\left(\frac{p+2 q}{3}\right)+\delta\left(\frac{q+r}{2}\right)+\lambda\left(\frac{2 r+s}{3}\right) \mu\left(\frac{v}{3}\right)+\delta\left(\frac{v}{2}\right)+\lambda\left(\frac{v}{3}\right)}{\mu+\delta+\lambda}\right) \text { (2) } \\
& \begin{array}{l}
\text { Published By: } \\
\text { Blue Eyes Intelligence Engineering } \\
\text { \& Sciences Publication }
\end{array} \text { Exploring Innovation }
\end{aligned}
$$


As a rare case, incentre of centroids for $\operatorname{TrFN~} \mathrm{P}=(\mathrm{p}, \mathrm{q}, \mathrm{r}$, $\mathrm{s}$; v) i.e. $\mathrm{r}=\mathrm{q}$ is described as

$$
I_{p}\left(e_{0}, f_{0}\right)=\left(\frac{\mu\left(\frac{p+2 q}{3}\right)+\delta q+\lambda\left(\frac{2 q+s}{3}\right)}{\mu+\delta+\lambda}, \frac{\mu\left(\frac{v}{3}\right)+\delta\left(\frac{v}{2}\right)+\lambda\left(\frac{v}{3}\right)}{\mu+\delta+\lambda}\right)
$$

The ranking of GTrFN, P = (p, q, r, s; v), which charts sets for all set of fuzzy numbers is declined as,

$$
R(P)=\left(\frac{\mu\left(\frac{p+2 q}{3}\right)+\delta q+\lambda\left(\frac{2 q+s}{3}\right)}{\mu+\delta+\lambda}, \frac{\mu\left(\frac{v}{3}\right)+\delta\left(\frac{v}{2}\right)+\lambda\left(\frac{v}{3}\right)}{\mu+\delta+\lambda}\right)
$$

Equation (3) described the region between the incentre of the centroids and the original point.

\section{SUGGESTED METHODOLOGY}

Step 1: Recognition of possible risk factors to frame a ranked risk breakdown framework.

Step 2: Choosing of suitable semantic scale to help specialist teams to articulating both probability of event and effect of risks (individual assessment).

Step 3: Semantic statistics (related to probability of event and effect of risk against every risk driver) are gathered from specialists through a group review. Subsequently, semantic statistics are converted to proper TrFN in accord with an assumed fuzzy scale set by the administration. A specialist team's pulled-opinion is needed to use 'Fuzzy aggregation regulation'.

Step 4: Aggregated fuzzy inclinations are calculated utilizing fuzzy aggregation regulation. The Fuzzy risk score of every risk driver is computed by multiplying 'aggregated fuzzy probability of event' with the 'aggregated fuzzy risk effect'. Step 5: Comparing crisp esteem against fuzzy risk score related to every risk driver is computed using the technique of 'Circumference of Centroids'. Also, various risk factors are positioned dependent on their crisp scores (pointer of the level of seriousness).

Step 6: Risk drivers are classified into different extents of seriousness dependent on the notion of risk matrix.

Step 7: Lastly, an activity prerequisite strategy is recommended for risk drivers be owned by various seriousness levels.

\section{CASE STUDY}

A case study was conducted in a leading herbal soap manufacturing company in India for validating the proposed method of risk assessment. The said company was dedicated to the development of healthcare products and services with a good reputation. They faced risks in the product development process for the past ten years almost every month throughout the year. Works are getting delayed due to the risks involved in the company. A focus group review was conducted for healthcare officials and supervisors related to development process. The group comprises five healthcare experts with over 10 years' experience in the healthcare sector. Expert's names are not mentioned in the paper because of anonymous reasons and they are termed as DM 1-5. In a questionnaire, the experts are invited to show their individual judgment based on a semantic scale. In the questionnaire, the risk evaluation factors are not indicated. All experts in the review work related to development process, and their knowledge helped the case study much.

\section{RESULT AND DISCUSSIONS}

The study describes the major problems of risk based on the empirical and the consequent administration strategy in the context of well-known Indian herbal soap manufacturing company. The efficiency of risk administration is accomplished by a vital survey of risk administration processes which includes recognizing, evaluating and controlling risks. A ranked structure is suggested to enable the process of risk recognition in the healthcare product development process. Seven possible risks like organizational risks, technology risks, communication risks, structural risks, product supplying risks, financial risks and environmental risks are recognized from a survey of existing healthcare literature. Each specific risk is described by its impacting factor. Main part of the work includes a case study being performed by deliberating a sum of 35 risk impacting factors that are recognized for the evaluation of total risk degree in the said healthcare sector. In this paper, the suggested approach calculates the risk level and proposes a risk alleviation strategy in the initial period of healthcare development process. For assessing and evaluating risks, this method described the fuzzy based MCDM method. Fuzzy notions are used to gather individual statistics on probability of event and information with respect to affect from recognized risk factors associated with healthcare development process. This increases expert's eagerness to provide insights into subjective risk evaluation. It is deliberated as a benefit that fuzzy numbers crisp values will provide sensitivity when the fuzzy semantic algorithm is examined. High level risk factor is to be observed, regulated and handled for increasing the efficiency of project. Hence, the paper is presented an action necessary strategy for recognized risk factors in diverse and specific classes which can be effectively observed, regulated and handled by risk proprietor, group, team of decision making and administration.

\section{CONCLUSION}

Effectual risk administration in the healthcare sector requires dependable risk assessment in addition to risk action planning followed by execution. The suggested risk assessment methodology was revealed to be pragmatic and dependable compared to conventional statistical techniques as it used risk experts insights. For calculating the risk ratings of both influence of risk and probability of event, this paper used the theory of fuzzy set and it is assessed by judgment of experts. The identified healthcare development process risks and their impacting factors are shown through a can simply be showed by the acquired ranked structure. The suggested approach not only evaluates the risk in the healthcare sector but also in the 
various scenarios. Case study was conducted in an Indian herbal soap manufacturing company for verifying the suggested approach. The research reveals a combined ranked risk evaluation method to provide a framework for risk administration in the healthcare sector where theory of fuzzy set replaced evaluation of probabilistic. Fuzzy number representation with crisp and also it enhances decision making by using the method of 'Incentre of Centroid'. Industrial managers will use our outcomes and the strategy of action for mitigating the risk. Investigation of risk evaluation methods will help healthcare managers understand varied risks related to the healthcare product company and their effect on total company achievement. For the achievement of company, action strategies was approved and confirmed by the risk managers for the purpose of controlling risks. Decrease of healthcare risks may improve suppleness and competitiveness in healthcare product companies against the present recession (collapse of healthcare sectors). This paper can be extended in varied directions. Initially, the current study uses trapezoidal fuzzy numbers to locate semantic depiction of risk evaluation; the paper can be used different kinds of fuzzy numbers for evaluating the risks. For the future perspective, more no of decision makers are required for rating the risk factors. Based on the healthcare suppliers' perspective, this study concentrates on healthcare risk recognition and quantification and also it can be verified by sellers and customers.

\section{ANNEXURE}

Table-I: Risk factors for HCPD process

\begin{tabular}{|c|c|}
\hline Factors & Sub-factors \\
\hline \multirow{5}{*}{ Organizational Risks $\left(\mathrm{R}_{1}\right)$} & Lack of Contingency plan $\left(\mathrm{R}_{1,1}\right)$ \\
\hline & $\begin{array}{l}\text { Working procedural knowledge \& } \\
\text { Compliance }\left(\mathrm{R}_{1,2}\right)\end{array}$ \\
\hline & Training/Knowhow $\left(\mathrm{R}_{1,3}\right)$ \\
\hline & Organization Commitment $\left(\mathrm{R}_{1,4}\right)$ \\
\hline & $\begin{array}{l}\text { Determining kinds of } \\
\text { products/product quantity }\left(\mathrm{R}_{1.5}\right)\end{array}$ \\
\hline \multirow{5}{*}{ Technology Risks $\left(\mathrm{R}_{2}\right)$} & Continuity of service $\left(\mathrm{R}_{2,1}\right)$ \\
\hline & Lack of use of technology $\left(\mathrm{R}_{2,2}\right)$ \\
\hline & $\begin{array}{l}\text { Data backup and network records } \\
\left(\mathrm{R}_{2,3}\right)\end{array}$ \\
\hline & Boxes for delivering products $\left(\mathrm{R}_{2,4}\right)$ \\
\hline & Loss of key technical person $\left(\mathrm{R}_{2,5}\right)$ \\
\hline \multirow{5}{*}{ Communication Risks $\left(\mathrm{R}_{3}\right)$} & $\begin{array}{l}\text { Information exchange according to } \\
\text { procedures }\left(\mathrm{R}_{3,1}\right)\end{array}$ \\
\hline & Communicating variations $\left(\mathrm{R}_{3,2}\right)$ \\
\hline & Variations in quantity/quality $\left(\mathrm{R}_{3,3}\right)$ \\
\hline & $\begin{array}{l}\text { Unclear decision-making process } \\
\left(\mathrm{R}_{3,4}\right)\end{array}$ \\
\hline & Feedback $\left(\mathrm{R}_{3,5}\right)$ \\
\hline \multirow{5}{*}{ Structural Risks $\left(\mathrm{R}_{4}\right)$} & Ordinary maintenance plans $\left(\mathrm{R}_{4,1}\right)$ \\
\hline & $\begin{array}{l}\text { Extraordinary maintenance plans } \\
\left(\mathrm{R}_{4,2}\right)\end{array}$ \\
\hline & Workplace Safety $\left(\mathrm{R}_{4,3}\right)$ \\
\hline & Service Interruptions $\left(\mathrm{R}_{4,4}\right)$ \\
\hline & Service Continuity $\left(\mathrm{R}_{4,5}\right)$ \\
\hline \multirow{5}{*}{ Product Supply Risks $\left(\mathrm{R}_{5}\right)$} & Quality of delivery products $\left(\mathrm{R}_{5,1}\right)$ \\
\hline & Documentation management $\left(\mathrm{R}_{5,2}\right)$ \\
\hline & $\begin{array}{l}\text { Inadequate terms \& Ambiguous } \\
\text { contract with supplier }\left(\mathrm{R}_{5,3}\right)\end{array}$ \\
\hline & Supplier service quality $\left(\mathrm{R}_{5,4}\right)$ \\
\hline & Delivery lead times $\left(\mathrm{R}_{5,5}\right)$ \\
\hline \multirow{5}{*}{ Financial Risks $\left(\mathrm{R}_{6}\right)$} & Supplier Assets $\left(\mathrm{R}_{6,1}\right)$ \\
\hline & Hidden costs $\left(R_{6,2}\right)$ \\
\hline & $\begin{array}{l}\text { Lack of planning \& inaccurate } \\
\text { budgeting }\left(\mathrm{R}_{6,3}\right)\end{array}$ \\
\hline & Contract specifications $\left(\mathrm{R}_{6,4}\right)$ \\
\hline & Ineffective infrastructure investment \\
\hline
\end{tabular}

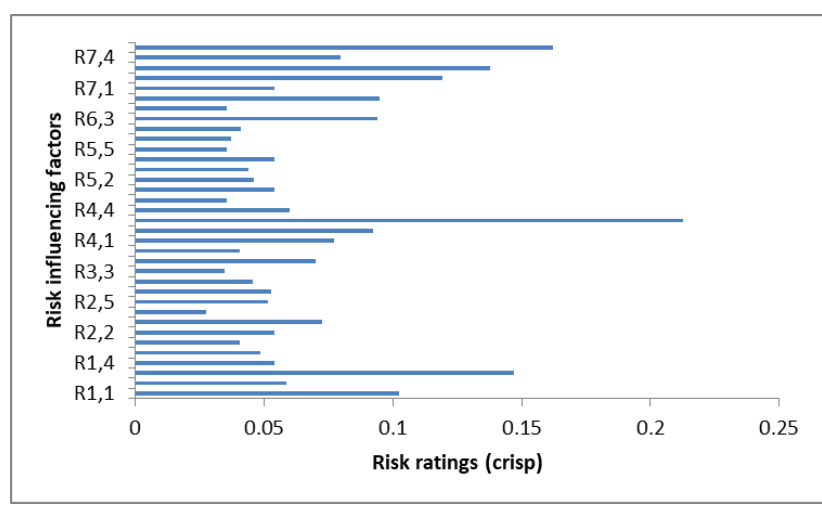

Fig. 1. Ratings of risk equivalent to every risk factor

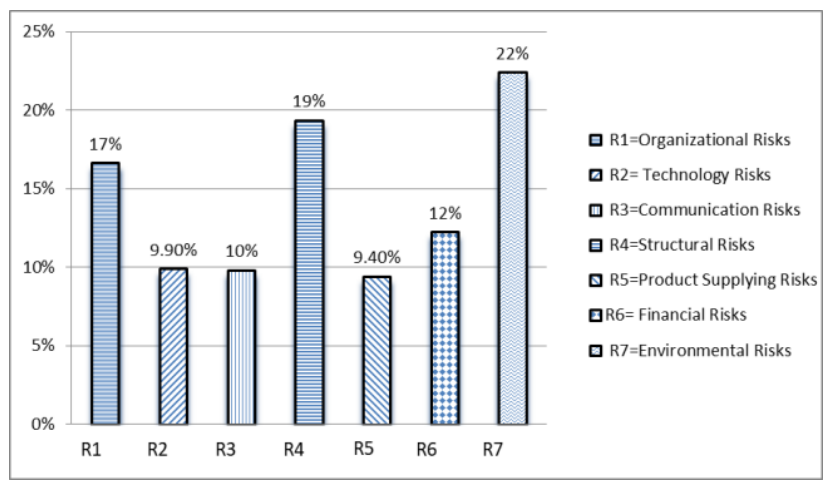

Fig. 2. Percentage contribution of every risk

Table- III: Recognition of risk factors in different risk

classifications and the need for the action to control the risk

\begin{tabular}{|c|c|c|}
\hline $\begin{array}{c}\text { Seriousness } \\
\text { level/Risk } \\
\text { score }\end{array}$ & Risk factors & Actions requisite \\
\hline
\end{tabular}




\begin{tabular}{|c|c|c|}
\hline $\begin{array}{l}5^{\text {th }} \text { category } \\
\text { Rating }(0.2499 \\
-0.2898)\end{array}$ & Not recognized & $\begin{array}{l}\text { Risk proprietor given the very } \\
\text { prompt warning to the team of } \\
\text { chief RM (suitable documents } \\
\text { needed) } \\
\text { Chief of team RM needs quick } \\
\text { inquiry. } \\
\text { For surveying the risk, a team of } \\
\text { committee assembly promptly. } \\
\text { Decision team put on high alert. } \\
\text { Risk group suggestions to be } \\
\text { relayed promptly to decision } \\
\text { team. team assesses, } \\
\text { Decision } \\
\text { favors/modifies action strategy. } \\
\text { Risk proprietor executes action } \\
\text { strategy. } \\
\text { RM team chief trails action } \\
\text { strategy outcomes. } \\
\text { Risk group surveys monthly } \\
\text { action strategy execution } \\
\text { outcomes. }\end{array}$ \\
\hline $\begin{array}{l}4^{\text {th }} \text { category } \\
\text { Rating }(0.1999 \\
-0.2498)\end{array}$ & $\mathrm{R}_{4,3}$ & $\begin{array}{l}\text { Risk proprietor given the prompt } \\
\text { warning to the team of chief RM } \\
\text { (suitable documents needed) } \\
\text { Chief of team RM needs quick } \\
\text { inquiry. } \\
\text { For surveying the risk, a team of } \\
\text { committee assembly promptly. } \\
\text { Decision team put on high alert. } \\
\text { Risk group suggestions to be } \\
\text { relayed to decision team at their } \\
\text { meetings. }\end{array}$ \\
\hline $\begin{array}{l}3^{\text {rd }} \text { category } \\
\text { Rating }(0.1499 \\
-0.1998)\end{array}$ & $\mathrm{R}_{7,5}$ & $\begin{array}{l}\text { Risk proprietor given the prompt } \\
\text { warning to the team of chief RM } \\
\text { (suitable documents needed) } \\
\text { Chief of team RM needs quick } \\
\text { inquiry. } \\
\text { For surveying the risk, a team of } \\
\text { committee assembly promptly. } \\
\text { At the meeting, risk group given } \\
\text { the suggestions to decision team. } \\
\text { Assesses, favors, and or modifies } \\
\text { the action strategy by decision } \\
\text { team. }\end{array}$ \\
\hline $\begin{array}{l}2^{\text {nd }} \text { category } \\
\text { Rating }(0.0999 \\
-0.1498)\end{array}$ & $\mathrm{R}_{1,1}, \mathrm{R}_{1,3}, \mathrm{R}_{7,2}, \mathrm{R}_{7,3}$ & $\begin{array}{l}\text { Risk proprietor given the prompt } \\
\text { warning to the team of chief RM } \\
\text { (suitable documents needed) } \\
\text { Chief of team RM needs quick } \\
\text { inquiry. } \\
\text { At monthly risk group meeting, } \\
\text { the risk can be assessed and } \\
\text { evaluated. } \\
\text { There is a need for action strategy. } \\
\text { Action strategy executed by risk } \\
\text { proprietor. }\end{array}$ \\
\hline $\begin{array}{l}1^{\text {rd }} \text { category } \\
\text { Rating }(0.0599 \\
-0.0998)\end{array}$ & $\begin{array}{l}\mathrm{R}_{2,3}, \\
\mathrm{R}_{3,4}, \mathrm{R}_{4,1}, \mathrm{R}_{6,3}, \mathrm{R}_{6,5}, \\
\mathrm{R}_{7,4}, \mathrm{R}_{4,2}\end{array}$ & $\begin{array}{l}\text { Chief of team RM needs quick } \\
\text { inquiry. } \\
\text { At monthly risk group meeting, } \\
\text { the risk can be assessed and } \\
\text { evaluated. } \\
\text { Delineated the action strategy. } \\
\text { If the rating of risk increases, } \\
\text { followed the additional action } \\
\text { plan. }\end{array}$ \\
\hline $\begin{array}{l}0^{\text {th }} \text { category } \\
\text { Rating }(0- \\
0.0598)\end{array}$ & $\begin{array}{l}\mathrm{R}_{1,2}, \mathrm{R}_{1,4}, \mathrm{R}_{1,5}, \mathrm{R}_{2,1}, \\
\mathrm{R}_{2,2}, \mathrm{R}_{2,4}, \mathrm{R}_{2,5}, \mathrm{R}_{3,1}, \\
\mathrm{R}_{3,2}, \mathrm{R}_{3,3}, \mathrm{R}_{3,5}, \mathrm{R}_{4,4}, \\
\mathrm{R}_{4,5}, \mathrm{R}_{5,1}, \mathrm{R}_{5,2}, \mathrm{R}_{5,3}, \\
\mathrm{R}_{5,4}, \mathrm{R}_{5,5}, \mathrm{R}_{6,1}, \mathrm{R}_{6,2}, \\
\mathrm{R}_{6,4}, \mathrm{R}_{7,1}\end{array}$ & $\begin{array}{l}\text { No need of quick action. } \\
\text { At any time, risk can be assessed } \\
\text { by the team of risk. } \\
\text { If the rating of risk increases, } \\
\text { followed the additional action } \\
\text { plan. }\end{array}$ \\
\hline
\end{tabular}

bad practice," Creativity and Innovation Management, Vol. 14(4), 2005, 425-437.

2. R. B. Handfield, R.B, G. L. Ragatz, K. J. Petersen and R. M. Monczka, "Involving suppliers in new product development," California management review, Vol. 42(1), 1999. 59-82.

3. J. A. Keizer, J. P. Vos and J. I.Halman, "Risks in new product development: devising a reference tool," R\&D Management, Vol. 35(3), 2005, 297-309.

4. T. P.Taylor and S. Ahmed-Kristensen, "Global product development projects: measuring performance and monitoring the risks," Production Planning \& Control, 2018.

5. W. Ajayi, Y. A. Adekunle, O. Awodele, A. O. Akinsanya and M. O. Eze, "Software Development Top Models, Risks Control and Effect on Product Quality," Global Journal of Computer Science and Technology, 2018.

6. H. G. Choi and J. Ahn, "Risk analysis models and risk degree determination in new product development: A case study," Journal of Engineering and Technology Management, Vol. 27(1-2), 2010, 110-124.

7. M. J. Chalupnik, D. C. Wynn and P. J. Clarkson, "Approaches to mitigate the impact of uncertainty in development processes," In DS 58-1: Proceedings of ICED 09, the 17th International Conference on Engineering Design, Vol. 1, Design Processes, Palo Alto, CA, USA, 24.-27.08. 2009, 459-470.

8. B. Kayis, G. Arndt, M. Zhou, and S. Amornsawadwatana, "A risk mitigation methodology for new product and process design in concurren engineering projects," CIRP Annals-Manufacturing Technology, Vol. 56(1), 2007, 167-170.

9. D. Unger and S. Eppinger, "Improving product development process design: a method for managing information flows, risks, and iterations," Journal of Engineering Design, Vol. 22(10), 2011, 689-699.

10. Z. Zhang and X. Chu, "Risk prioritization in failure mode and effects analysis under uncertainty," Expert Systems with Applications, Vol. 38(1), 2011, 206-214.

11. B. Shaw, "Innovation and new product development in the UK medical equipment industry," International Journal of Technology Management, Vol. 15(3-5), 1998, 433-445.

12. S. L. Chan, W. H. Ip, and W. J. Zhang, "Integrating failure analysis and risk analysis with quality assurance in the design phase of medical product development," International Journal of Production Research, Vol. 50(8), 2012, 2190-2203.

13. M. S. Kirkire, S. B. Rane and J. R. Jadhav, "Risk management in medical product development process using traditional FMEA and fuzzy linguistic approach: a case study," Journal of Industrial Engineering International, Vol. 11(4), 2015, 595-611.

14. S. Muthuperumal, P. Titus and M. Venkatachalapathy, "A study on solving generalized trapezoidal fuzzy transportation problem with mixed constraints using ranking function," 2018.

15. A. Kumar, P. Singh, A. Kaur and P. Kaur, "Ranking of generalized trapezoidal fuzzy numbers based on rank, mode, divergence and spread," Turkish Journal of Fuzzy Systems, Vol. 1(2), 2015, 141-152.

16. R. Jain, "Decision making in the presence of fuzzy variables," 1976.

17. X. Wang and E. E. Kerre, "Reasonable properties for the ordering of fuzzy quantities (I)," Fuzzy sets and systems, Vol. 118(3), 2001, 375-385.

18. Y. L. P. Thorani, P. P. B. Rao and N. R. Shankar, "Ordering generalized trapezoidal fuzzy numbers using orthocentre of centroids," International Journal of Algebra, Vol. 6(22), 2012, 1069-1085.

\section{AUTHORS PROFILE}

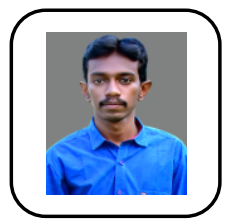

R.K.A.Bhalaji obtained his B.E (MECH) in 2014 from the K.L.N.College of Engineering, Madurai, Tamilnadu, India. He completed his M.Tech (Industrial Safety Engineering) in 2016 at the Kalasalingam Academy of Research and Education, Krishnankoil, Tamilnadu, India. Currently, he is a Research Scholar in the Department of Mechanical Engineering, Kalasalingam Academy of Research and Education, Krishnankoil, Tamilnadu, India. His research interests include multi-criteria decision making and application of fuzzy set theory in real life decision problems. He is currently pursuing PHD in the area of analysis of risk factors for the identification and evaluation for finding influential risk factors in healthcare industries by using MCDM methods.

\section{REFERENCES}

1. E. Enkel, J. Perez - Freije and O. Gassmann, "Minimizing market risks through customer integration in new product development: learning from 
Dr.S.Bathrinath is an Associate Professor in the Department of Mechanical Engineering, Kalasalingam Academy of Research and Education, Krishnankoil, Tamilnadu, India. His current area of research includes multi-criteria decision making, scheduling \& optimization, soft computing and Artificial intelligence. He has published a number of papers in journal of national/international repute and presented a number of papers in various conferences/symposia in India and abroad. He is presently guiding a number of master/doctoral research scholars. Dr.S.Bathrinath is the corresponding author and can be contacted at: bathri@gmail.com

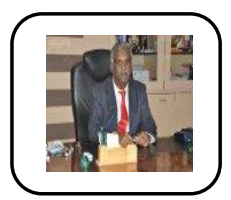

Dr.S.Saravanasankar is a Senior Professor in the Department of Mechanical Engineering, Kalasalingam Academy of Research and Education, Krishnankoil, Tamilnadu, India. He has more than 20 years of experience in teaching and research. His current area of research includes scheduling, optimization and multi-criteria decision making. He has published more than 40 research articles in journals of national and international repute. 